УДК 331. 1

\title{
СОВЕРШЕНСТВОВАНИЕ МЕХАНИЗМА РЕАЛИЗАЦИИ КАДРОВОЙ ПОЛИТИКИ В ТРАНСПОРТНОЙ ОТРАСЛИ
}

\author{
Маликова Яна Ивановна \\ кандидат экономических наук, доцент \\ Институт образовательных технологий и гуманитарных наук \\ Горелов Дмитрий Владимирович \\ кандидат экономических наук, доцент \\ Институт образовательных технологий и гуманитарных наук \\ Данилина Елена Ивановна \\ доктор экономических наук, профессор \\ МИРЭА - Российский технологический университет
}

\begin{abstract}
Аннотация: В статье показана особенность реализации программноцелевого метода управления персоналом в транспортных организациях. Основное внимание уделено отдельным проблемам методологического характера. Показано, что используемые методы целеполагания не позволяют транспортным компаниям поставить максимально точные и конкретные цели. Обосновано, что имеющиеся проблемы не позволяют в полной мере осуществить оценку соответствия достигнутых результатов с целевыми критериями управления персоналом.
\end{abstract}

Ключевые слова: человеческие ресурсы, кадровая политика, управление персоналом, транспортный комплекс.

\section{MPROVING THE MECHANISM FOR IMPLEMENTING PERSONNEL POLICY IN THE TRANSPORT INDUSTRY}

\author{
Malikova Yana Ivanovna \\ Gorelov Dmitry Vladimirovich \\ Danilina Elena Ivanovna
}

\begin{abstract}
The article shows the peculiarity of the implementation of the program-target method of personnel management in transport organizations. The main attention is paid to certain methodological problems. It is shown that the goalsetting methods used do not allow transport companies to set the most accurate and
\end{abstract}


specific goals. It is proved that the existing problems do not allow to fully assess the compliance of the achieved results with the target criteria of personnel management.

Key words: human resources, personnel policy, personnel management, transport complex.

Сохранение и развитие кадрового потенциала отрасли, совершенствование системы отраслевой подготовки и переподготовки кадров являются общими, обеспечивающими задачами по достижению целей Транспортной стратегии [5].

Для выполнения поставленной задачи в Транспортной стратегии укажем следующие три группы мероприятий по направлениям:

- Государственное регулирование в сфере кадрового обеспечения видов транспорта

В рамках данного направления предусмотрены меры по совершенствованию системы подготовки, переподготовки и повышения квалификации в отраслевой образовательной система транспортной отрасли, совершенствованию программ подготовки с применением специализированных тренажеров и с учетом меняющихся рыночных условий и требований к качеству профессиональной подготовке специалистов. На отраслевые органы управления транспортным комплексом возлагаются функции по разработке нормативных правовых актов, регламентирующих трудовые и финансовые взаимоотношения специалиста с потенциальным работодателем, оплатившим его обучение.

- Развитие человеческих ресурсов

В рамках данного направления предпринимаются меры по обеспечению всех уровней транспортной отрасли профессионально подготовленными специалистами массовых профессий, которые ориентированы на длительные трудовые отношения и выстраивание профессиональной карьеры, а также осуществляется содействие в создании корпоративных систем управления персоналом, систем мотивации и повышения производительности труда

Основными механизмами реализации кадровой политики в транспортной отрасли являются:

а. Организационный механизм реализации государственной кадровой политики в транспортной отрасли.

В настоящее время государственные функции по подготовке кадров для транспортной отрасли на федеральном уровне осуществляют Министерство 
транспорта РФ и входящие в его структуру пять Федеральных агентств: Росавиация, Росавтодор, Росжелдор, Росморречфлот, Росавтотранс.

В ходе реализации отраслевой кадровой политики обеспечивается непрерывное взаимодействие данных структур с другими федеральными органами исполнительной власти, такими как Министерство просвещения РФ, Министерство труда и социальной защиты РФ, Министерство финансов РФ, органами исполнительной власти субъектов РФ, муниципальных образований и др.

Следует отметить, что в настоящее время на государственном уровне отсутствует система мониторинга кадровых потребностей и достижения целевых показателей кадрового развития транспортной отрасли. Отсутствие единой системы государственного статистического учета в сфере кадрового обеспечения и уровня развития кадрового потенциала транспортной отрасли в настоящее время не позволяет проводить аналитические оценки и выявлять проблемные участки в отраслевой кадровой политике.

b. Институциональный механизм реализации отраслевой кадровой политики.

Институциональный механизм реализации отраслевой кадровой политики в транспортной отрасли включает разработку стратегий развития отдельных видов транспорта, подготовку отраслевых и региональных программ, указов Президента РФ, Постановлений Правительства РФ, регламентов и т.д.

Одним из основных направлений государственного регулирования рынка труда является сфера занятости населения. В настоящее время реализуется государственная программа [4], в рамках которой все мероприятия сгруппированы в три приоритетных направления:

- Проведение активной политики занятости населения и социальная поддержка безработных граждан,

- Институциональное развитие рынка труда

- Мероприятия по охране и созданию безопасных условий труда.

Реализация мероприятий в области поддержки занятости осуществляется в рамках федерального проекта «Поддержка занятости и повышение эффективности рынка труда для обеспечения роста производительности труда» в соответствии с Указом Президента РФ [9].

В рамках проектных мероприятий осуществляется взаимодействие сторон социального партнерства - Минтрудом России, Пенсионным фондом РФ, Федерацией Независимых Профсоюзов России (ФНПР), Российским союзом 
промышленников и предпринимателей (РСПП) - по наиболее актуальным вопросам трудового законодательства.

В настоящее время кадровая политика в отрасли регламентируется такими документами, как «Транспортная стратегия РФ на период до 2030 года» [5], «Стратегия развития внутреннего водного транспорта РФ» [6], «Стратегия развития железнодорожного транспорта в РФ до 2030 года» [7]. Отдельные аспекты кадрового обеспечения отражаются в ведомственных целевых программах Министерства транспорта РФ [1].

c. Механизм государственной поддержки отраслевых ВУЗов транспортного образования, осуществляющих подготовку научных кадров.

Для ВУЗов, реализующих программы развития, направленные на повышение научного, образовательного и инновационного потенциала, обеспечение привлекательности работы в транспортной отрасли для российских и зарубежных ученых и молодых перспективных исследователей, Правительство РФ планирует предоставлять гранты в форме субсидий.

В настоящее время остается дискуссионным вопрос о выборе наиболее эффективной методики целеполагания в кадровой работе. На уровне предприятий транспортной отрасли цели кадровой политики отражают конечный результат системы управления персоналом за определенный период времени, к которому стремится компания.

Крупные транспортные компании, являющиеся лидерами в отрасли, учитывают глобальные изменения на рынке и формулируют стратегические цели кадровой политики на среднесрочный и долгосрочный период. Так, например, стратегическая цель системы управления персоналом ОАО «РЖД» до 2030 года состоит в том, чтобы «привлекать к работе лучших специалистов, гарантируя конкурентоспособность заработной платы, улучшение условий труда, современный социальный пакет» [2].

Стратегическая цель крупнейшей авиационной группы компании «Аэрофлот» до 2028 года заключается в «повышении эффективности работы и производительности труда благодаря созданию уникальной команды высокопрофессиональных и вовлеченных сотрудников» [3].

В то же время, большинство компаний слабо используют стратегическое целеполагание при разработке кадровой политики. Более того, результаты прикладных исследований показывают, что в настоящее время значительная часть компаний не имеют формализованной кадровой политики. Так, например, согласно резолюции отраслевой научно-методической конференции «Кадровый потенциал предприятий водного транспорта-2016» официально утвержденную 
кадровую политику на среднесрочный период имели всего 18 из 230 опрошенных предприятий. Это не позволяет создать полноценную картину кадровой потребности отрасли.

В стратегических документах развития транспортной отрасли, также, как и у многих транспортных компаний цели кадровой политики сформулированы недостаточно четко и в большинстве случаев не соответствуют принципам конкретности и измеримости. Поскольку в кадровой политике отсутствуют количественные критерии, оценка результативности выполнения стратегических программ в области формирования и развития кадрового потенциала вызывает существенные проблемы.

Кроме того, к проблемным и спорным вопросам относятся вопросы, связанные с выбором эффективных механизмов координации и согласования программ развития транспортных разделов региональных и муниципальных программ социально-экономического развития. При наличии расхождений между интересами органов власти различных уровней и транспортных компаний, достижение поставленных целей кадровой политики в транспортной отрасли может быть поставлено под угрозу.

Таким образом, при реализации программно-целевого метода управления персоналом транспортные организации сталкиваются с рядом проблем методологического характера. Используемые методы целеполагания не позволяют транспортным компаниям поставить максимально точные и конкретные цели, что ведет к наличию неопределенностей и двусмысленности целевых установок и не позволяет в полной мере осуществить оценку соответствия достигнутых результатов с целевыми критериями управления персоналом.

\section{Список литературы}

[1] Ведомственная целевая программа Министерства транспорта Российской Федерации. Организационное, информационное и научное обеспечение реализации государственной программы РФ «Развитие транспортной системы»

[2] Годовой отчет ОАО РЖД за 2019 год.

https://ar2019.rzd.ru/download/full-reports/ar_ru_annualreport_spreads_rzd_2019.pdf

[3]Годовой отчет ГК Аэрофлот. Кадровая политика. https://ar2018.aeroflot.ru/reports/aeroflot/annual/2018/gb/Russian/204515/.html 
[4] Постановление Правительства Российской Федерации от 30.03.2020 № 370 «Об утверждении государственной программы Российской Федерации «Содействие занятости населения». Официальный интернет-портал правовой информации Гарант http://pravo.garant.ru/document?id=70543477\&byPara=1

[5] Распоряжение Правительства Российской Федерации №1734-p от 22.11.2008 г. Об утверждении транспортной стратегии Российской Федерации на период до 2030 года (с изм. на 12 мая 2018 г.) http://docs.cntd.ru/document/902132678

[6] Распоряжение Правительства Российской Федерации №327-р от 29.02.2016. «Об утверждении стратегии развития внутреннего водного транспорта Российской Федерации на период до 2030 года

[7] Распоряжение Правительства Российской Федерации № 877-р от 17.06.2008 г. Стратегия развития железнодорожного транспорта в Российской Федерации до 2030 года

[8] Распоряжение Правительства Российской Федерации № 1734-р от 22.11.2008 г. «Об утверждении транспортной стратегии Российской Федерации на период до 2030 года (с изм. на 12 мая 2018 г.) http://docs.cntd.ru/document/902132678

[9] Указ Президента Российской Федерации № 204 от 7.05 .2018 г. «О национальных целях и стратегических задачах развития Российской Федерации на период до 2024 года»

(C) Маликова Я.И., Горелов Д.В., Данилина Е.И., 2021 